\title{
A Comparative study of efficacy of high dose versus low dose of suxamethonium for endotracheal intubation
}

\author{
R.K. Yadav ${ }^{1}$, P.C. Majhi², B.B. Pradhan ${ }^{3}$ \\ Lecturer ${ }^{1}$, Professor and Head ${ }^{2}$, Resident $^{3}$ Department of Anesthesiology, College of Medical Sciences, \\ Bharatpur, Chitwan, Nepal
}

\begin{abstract}
As use of suxamethonium is associated with a large number of undesirable and serious side effects, including cardiac arrhythmias and malignant hyperthermia. These undesirable effects have prompted anesthesiologists to restrict use of suxamethonium. The low dose of the drug is expected to have lower side effects without compromising its neuromuscular blocking properties as the dose dependent side effects have been known for long, so the present study carried out to compare the efficacy of high dose $(1.5 \mathrm{mg} / \mathrm{Kg})$ of suxamethonium to that of low dose $(0.5 \mathrm{mg} / \mathrm{Kg})$ assessed by intubation condition with neuromuscular blockade. We prospectively randomized and compared the intubating conditions with neuromuscular monitoring in 100 patients undergoing elective abdominal, gynaecological and limb surgery in CMS-TH and found duration of apnoea and time taken for recovery of twitch height was significantly shorter. Without compromising the quality of neuromuscular blockade. Suxamethonium or Succinylcholine can be used in lower doses $(0.5 \mathrm{mg} / \mathrm{kg})$ in elective cases without airway compromise to achieve intubation.
\end{abstract}

Key Word: Suxamethonium, neuromuscular, monitoring, intubating conditions.

\section{Introduction}

Succinylcholine also known as suxamethonium is a depolarizing type of neuromuscular blocking drug. Rapid onset and short duration of neuromuscular block produced by this drug is unique amongst the neuromuscular blocking drugs described so far. ${ }^{1}$ There have been many efforts to reduce the period of onset of action of other neuromuscular blocking drugs by using large doses or by employing priming principle but no drug has been noticed to produce adequate intubating

Correspondence: R.K. Yadav

E-mail: drrajeshyadav@yahoo.com conditions in less than 90 seconds including newer drugs like mivacurium and rocuronium. ${ }^{2,3}$ It produces adequate intubating conditions within 3040 seconds which lasts for 6-7minutes in dosages used in anesthetic practice. With these features, suxamethonium seems to be appropriate relaxant in various clinical settings like short surgical procedures, reduction of fractures, difficult airways, electroconvulsive therapy, endoscopies etc.

However, use of suxamethonium is associated with a large number of undesirable and serious side effects, including cardiac arrhythmias and 
malignant hyperthermia. These undesirable effects have prompted anesthesiologists to restrict use of suxamethonium. Much affords, including dose reduction, have been attempted to get rid of side effects. Usual intravenous dose of suxamethonium is $1-1.5 \mathrm{mg} / \mathrm{kg}$ of body weight. ${ }^{4}$ The low dose of the drug is expected to have lower side effects without compromising its neuromuscular blocking properties as the dose dependent side effects have been known for long. ${ }^{5,6,7}$ The present study attempts to evaluate efficacy of lower than conventional doses of suxamethonium with special reference to intubation. Objective of the study was to compare the efficacy of high dose $(1.5 \mathrm{mg} / \mathrm{Kg})$ of suxamethonium to that of low dose $(0.5 \mathrm{mg} / \mathrm{Kg})$ as assessed by intubation condition with neuromuscular blockade.

\section{Materials and methods}

A total of 100 patients attending for elective abdominal, gynecological and limb surgery in COMS-Teaching Hospital, Bharatpur (Chitwan) were studied. Informed consent was taken before the enrollment of the patients in the study. All these patients on preoperative clinical evaluation were assessed to have adequate airway and belonged to class I or II of Mallampati classification. ${ }^{8}$ Patients in class III or IV airways were excluded. Enrolled patients were randomly allocated in two groups in equal numbers i.e. 50 patients in each group and received medications as follows:

Group I: $0.5 \mathrm{mg} / \mathrm{kg}$ of suxamethonium.

Group II: $1.5 \mathrm{mg} / \mathrm{kg}$ of suxamethonium.

A standard anesthetic technique was adhered to in all these patients. All patients in both groups received premedication with diazepam $0.02 \mathrm{mg} / \mathrm{kg}$ the prior night and in the morning on the day of surgery. On the table an intravenous line using normal saline was started and baseline blood pressure recording were made. At the same time electrodes of peripheral nerve stimulator were also attached over right hand ulner nerve for monitoring twitch heights. Induction of anesthesia was achieved with inj. Propofol upto a maximum of $2.5 \mathrm{mg} / \mathrm{kg}$ given over 20-30 seconds. After further 30 seconds, suxamethonium at the dose of $0.5 \mathrm{mg} /$ $\mathrm{kg}$ or $1.5 \mathrm{mg} / \mathrm{kg}$ administered to the patient of respective group. As twitch height was observed to fall to $10 \%$ of control after administration of suxamethonium, direct laryngoscopy was performed and trachea was intubated. Thereafter anesthesia was maintained using oxygen, nitrous oxide, halothane and/or long acting relaxants wherever indicated. Following parameters were recorded as per predefined structured Performa. Degree of jaw relaxation, vocal cord relaxation and overall assessment of intubating conditions at the time of laryngoscopy according to schemes adopted by Twohig et al. ${ }^{9}$ Time when twitch height fell to $0 \%$ of control and recovered to $100 \%$ of control was noted and time of resumption of spontaneous breathing effort was also noted. Neuromuscular Monitoring for peripheral nerve blockade done by use of TOF-guard (Biometer, Denmark) which was measured by twitch height in response to ulnar nerve. For monitoring of neuromuscular transmission, surface electrode of biometer accelograph was fixed on ulnar side of volar surface of wrist and the transducer fixed on corresponding thumb. 
R.K. Yadav et al, A Comparative study of efficacy of high dose versus low dose of

Statistical analysis was done using Epi-Info 12 software. Data pertaining to twitch height monitoring was analyzed by $\mathrm{Z}$ test. For comparison between the two multiple linear regression analysis was undertaken controlling for baseline variables. Statistical significance was taken as $\mathrm{p}<0.05$.

\section{Results}

Demographic data are comparable in both groups $(\mathrm{P}<0.74)$. Overall intubating conditions were found to be comparable in both groups. Excellent intubating condition was recorded in 47 (94\%) in high dose in comparison to $40(80 \%)$ patients in low dose. Jaw relaxation was good in both groups in high percentage of patients. $92 \%$ of patients in high dose group had good cord relaxation as against $84 \%$ in group I.
Single twitch height recordings are presented in table-1. In all the patients of low dose group, intubation could be achieved within a mean of 44(2.6) seconds, which corresponded to reduction of twitch height to $10 \%$ of control. However, in high dose group twitch height fall to $10 \%$ of control within 36 (2.90) seconds $(\mathrm{p}<0.001)$. Apnoea was significantly prolonged in group II with a mean duration of 502 (56) seconds whereas in low dose group, it was 312 (70) seconds $(\mathrm{p}<0.001)$. Table-2 shows distribution of cases in both groups as regards fall of twitch height to $10 \%$ of control. In group I it took place within 40-50 seconds in most (94\%) of cases whereas in $90 \%$ of cases of group II, it was observed to be between 30-40 seconds. All the patients in both the groups demonstrated a reduction in twitch height to $10 \%$ within 55 seconds.

Table-1: twitch height reduction and recovery data recorded by accelograph [value expressed as mean (SD) seconds].

\begin{tabular}{ccccc}
\hline $\begin{array}{c}\text { Twitch } \\
\text { height }\end{array}$ & $\begin{array}{c}10 \% \text { of } \\
\text { control }\end{array}$ & $\begin{array}{c}0 \% \text { of } \\
\text { control }\end{array}$ & $\begin{array}{c}\text { Spontaneous breath } \\
\text { reappears at }\end{array}$ & $\begin{array}{c}100 \% \text { recovery } \\
\text { to control }\end{array}$ \\
\hline Group I (low) & $44(2.60)$ & $60(4.05)$ & $312(70.17)$ & $408(80.3)$ \\
Group II (high) & $36(2.90)$ & $56(2.86)$ & $502(55.65)$ & $575(75.75)$ \\
\hline
\end{tabular}

Table 2: Time taken for twitch height to fall to $10 \%$ of control: distribution of cases in both groups

\begin{tabular}{lccccccc}
\hline Time (sec) & 30 & $31-35$ & $36-40$ & $41-45$ & $46-50$ & $51-55$ & $56-60$ \\
\hline Group I (low) & Nil & Nil & 2 & 30 & 17 & 1 & Nil \\
Group II (high) & 1 & 24 & 21 & 4 & Nil & Nil & Nil \\
\hline
\end{tabular}

\section{Discussion}

Suxamethonium can be used in lower doses $(0.5$ $\mathrm{mg} / \mathrm{kg}$ ) in elective cases without airway compromise to achieve intubation. In the present study twitch height depression of $90 \%$ was taken to be the point at which intubation was attempted in both the groups. Although time taken for twitch height to fall to $10 \%$ of control was significantly shorter in high dose group intubating conditions were comparable in both groups. Ninety four 
Journal of College of Medical Sciences-Nepal, 2011, Vol-7, No-4

percent of cases could be intubated without difficulty with mean time of $44 \pm 2.6$ seconds in low dose group for $90 \%$ twitch height depression. Bucking or slight coughing did occur in certain low dose group patients but this could be avoided easily by keeping the time gap between Propofol and Suxamethonium to the minimum. In addition prior manual standardization of neuromuscular monitor also reduced the incidence. Automatic standardization of twitch height after administration of Propofol was time consuming and a waiting period between Propofol and Suxamethonium was necessary to allow the same. Twitch height also felt to zero in all the patients. Neuromuscular block achieved in both the groups was comparable for the period when twitch height was zero and before recovery began as tested by ulnar nerve stimulation. It could be argued, however, that since respiratory muscles including diaphragm are less sensitive to neuromuscular blocking agent than the peripheral muscle, peripheral nerve stimulation may not give true picture of existing neuromuscular block. ${ }^{10}$

Low-dose group study cohort also had advantage of short apnea period (312 \pm 70 seconds) than high dose group. Miller et al (1971) established ED95 for Suxamethonium to be $0.2 \mathrm{mg} / \mathrm{kg}$. ${ }^{11}$ Since in clinical practice relaxants are used in dosages of 2 $\mathrm{x}$ ED95 to achieve intubation, it provides a reason to use lower dose on the basis of pharmacological principles. Suxamethonium has also been used in dose of $0.7 \mathrm{mg} / \mathrm{kg}$ to provide adequate intubating conditions within 60 seconds. ${ }^{12}$ Overall intubating conditions were judged to be similar in both groups. Though higher proportion of patients in group II had excellent condition. Therefore, it is pertinent to use low-dose of Suxamethonium for the intubation of patients during surgery. However, it is stressed that in cases where rapid sequence induction is required because of high risk of airways contamination, larger dose of suxamethonium should be used only to ensure optimal intubating condition in every case unless one is well conversant with low dose of suxamethonium.

\section{Conclusion}

Present study, supported by reports in literature demonstrates that twitch height depression to $10 \%$ of control occurs delayed in low-dose group but duration of apnoea and time taken for recovery of twitch height is significantly shorter without compromising of neuromuscular blockade. Suxamethonium or Succinylcholine can be used in lower doses $(0.5 \mathrm{mg} / \mathrm{kg})$ in elective cases without airway compromise to achieve intubation.

\section{References}

1. J.A. Castillo, E.J. Debeer. Neuromuscular blocking action of suxamethonium. $J$ of pharmacol Exp Ther 1950; 97:458.

2. S. Schwarz, W. Ilias, F. Lackner. rapid trachel intubation with vecuronium. The priming principle. Anesthesiology 1985;62:388-93.

3. J.J. Savarese, H.H. Ali, S.J. Basta et al. the clinical neuromuscular pharmacology of mivacurium chloride. Anesthesilogy. 1988;68:723-32.

4. Froancois Donati and David R. Brevan . Neuromuscular Blocking Agents . In : P.G. Barash, B.F. Cullen, R.K. Stoeling. Clinical Anesthesia, 5 th ed.Lippincott Williams and Wilkins, Philadelphia. 2006; 427. 
R.K. Yadav et al, A Comparative study of efficacy of high dose versus low dose of

5. K.G. Stewart, P.M. Hopkins, S.G. Dean. Comparision of high and low doses of suxamethonium. Anesthesia 1991;46:833-6.

6. C.B. Collier. Suxamethonium pains and early electrolyte changes. Anesthesia 1978; 33:454.

7. J. Viby-Mogensen correlation of suxamethonium duration of action with plasma cholinesterase activity in subjects with genotypically normal enzyme. Anesthesilogy 1980;53:513-20.

8. S.R. Mallampatti, S.P. Galt, L.D. Gugino et al. A clinical sigh to predict difficult intubation : a prospective study. Can Anesth Society Journal 1985;32:429-34.
9. M.M. Twohig, S. ward, I.M. Corall. Condition for tracheal intubation using atracurium compared with pancuronium. Brit J Anes 1983;55:875-95.

10. J. Viby-Mogensen. neuromuscular monitoring. In Miller RD (editor) anesthesia vol II, Churchill Livingstone $1990 ; 1223$.

11. R.D. Miller, W.L. Way, W.M. Dolan et al. comparative neuraomuscular effects of pancuronium, gallamine and suxamethonium during fluorine and halothane anesthesia in man. Anesthesiology 1971;35:509-14.

12. R.D. Miller, J.J. Savarese. Pharmacology of muscle relaxants and their antagonists: In Miller RD (Ed). Anesthesia vol I Churchill Livingstone 1990;412. 